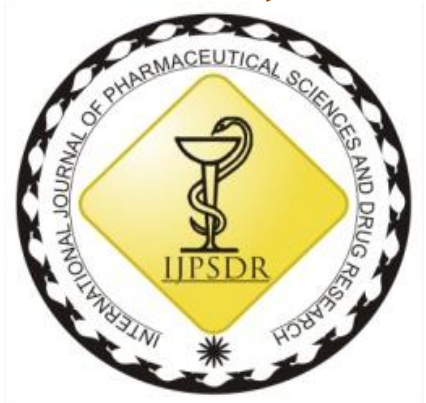

ISSN: 0975-248X

Research Article CODEN (USA): IJPSPP

(cc) BY-NC-SA

\title{
Antiulcer Activity of Methanolic Extract of Roots of Beta vulgaris, Chenopodiaceae
}

\author{
Manoj Jagannath Jagtap', Amol Bhalchandra Deore ${ }^{2 *}$ \\ 1Department of Pharmacology, Mahatma Gandhi Vidyamandir's Institute of Pharmacy, Malegaon-423203, \\ Nashik, Maharashtra, India \\ 2Department of Pharmacology, Maratha Vidya Prasarak Samaj's Institute of Pharmaceutical Sciences, Adgaon-422003, \\ Nashik, Maharashtra, India
}

Copyright (C) 2018 Manoj Jagannath Jagtap et al. This is an open access article distributed under the terms of the Creative Commons Attribution-NonCommercial-ShareAlike 4.0 International License which allows others to remix, tweak, and build upon the work noncommercially, as long as the author is credited and the new creations are licensed under the identical terms.

\begin{abstract}
Beta vulgaris (chenopodiacea) is a medicinal plant reported for its variety of ethnic medicinal uses. Beta vulgaris showed antioxidant, anticancer, hepatoprotective, nephroprotective, wound healing, and anti-inflammatory activities. Hence we have planned to screen antiulcer activity of root of the plant with the methanolic extract. Root powders successively extracted with methyl alcohol and were subjected for phytochemical screening to identify different phytoconstituents. The methanolic extracts of roots of Beta vulgaris were investigated for ulcer protective activity against pyloric-ligation, ethanol induced gastric lesion and cold restraint stress induced ulcers. Preliminary phytochemical screening revealed the presence of flavonoids, saponins, sterols, and alkaloids. The extract was tested for their lethal effect up to the dose level of $2000 \mathrm{mg} / \mathrm{kg}$. None of them have produced abnormal behavior or mortality in rats. Further methanolic extract of 200 and $400 \mathrm{mg} / \mathrm{kg} / \mathrm{p} .0$ significantly $(p<0.01)$ reduced the ulcer score, ulcer number, ulcer index, free acidity and total acidity in pyloricligation, ethanol induced gastric lesion and cold restraint stress induced ulcer models in rats. The present study revealed that the root extract of Beta vulgaris has antiulcer activity.
\end{abstract}

Keywords: Pyloric-ligation, gastric lesion, ulceration, wound healing.

DOI: 10.25004/IJPSDR.2018.100605

Int. J. Pharm. Sci. Drug Res. 2018; 10(6): 454-459

*Corresponding author: Mr. Amol Bhalchandra Deore

Address: Department of Pharmacology, Maratha Vidya Prasarak Samaj's Institute of Pharmaceutical Sciences, Adgaon-422003, Nashik,

Maharashtra, India

Tel.: +91-9011176272

E-mail $\bowtie$ : amoldeore22@gmail.com

Relevant conflicts of interest/financial disclosures: The authors declare that the research was conducted in the absence of any commercial or financial relationships that could be construed as a potential conflict of interest.

Received: 14 August, 2018; Revised: 06 October, 2018; Accepted: 12 October, 2018; Published: 20 November, 2018

\section{INTRODUCTION}

Peptic ulcer (encompassing gastric ulcer and duodenal ulcer) is a major health hazard both in terms of morbidity and mortality. A peptic ulcer results from an imbalance between some endogenous aggressive factors [hydrochloric acid, pepsin, refluxed bile, leukotrienes, reactive oxygen species (ROS)] and cytoprotective factors, which include the function of the mucus-bicarbonate barrier, surface active phospholipids, prostaglandins (PGs), mucosal blood 
flow, cell renewal and migration, nonenzymatic and enzymatic antioxidants and some growth factors. [1-4] Peptic ulcer disease affect a large portion of the world population and are induced by several factors, including stress, smoking, nutritional deficiencies, and ingestion of non-steroidal anti-inflammatory drugs. [5] The pathophysiology of these ulcers involves an imbalance between offensive (acid, pepsin, and Helicobacter pylori) and defensive factors (mucin, prostaglandin, bicarbonate, nitric oxide and growth factors). Today, there are two main approaches for treating peptic ulcer. The first deals with reducing the production of gastric acid and the second with reenforcing gastric mucosal protection. [6] Peptic ulcer disease and gastric dyspepsia-associated with chronic use of therapeutic agents such as non-steroidal antiinflammatory drugs (NSAIDs) and anticancer agents are the two major causes that adversely affect the life quality. Presently used antisecretory agents like proton pump inhibitors may represent a key option in peptic ulcer therapy ${ }^{[7]}$ but their prolonged use seems to be associated with high incidence of hip fractures. NSAIDs induced gastropathy remains a major clinical problem ${ }^{[4]}$ which has not been solved through the introduction of selective inhibitors of cyclooxygenase-2 (COX-2) due to cardiac side effects. [8] The World Health Organization $(\mathrm{WHO})$ has estimated that there are about 2 billion people worldwide who consume alcoholic beverages and 76.3 million with diagnosable alcohol use disorders. Alcohol consumption is an important factor to induce the gastric ulcer.

Over recent years, abundant work has been accomplished to develop natural products to potentially provide rich sources of new agents with anti-ulcer activity. It is significant to clarify their prevention or management action against gastric ulcer. A few of plant extracts and plant-derived compounds have been found and proved to be safe, effective, relatively less expensive and globally competitive. [9-10] Beetroot (Beta vulgaris) is botanically classified as an herbaceous biennial from Chenopodiaceae family and has several varieties with bulb colors ranging from yellow to red. Deep red-colored beet roots are the most popular for human consumption, both cooked and raw as salad or juice. [11] It is cultivated as a vegetable almost throughout India. ${ }^{[12-14]}$ B. vulgaris leaves stated diuretic, purgative, laxative, and aphrodisiac activity. [15-16] B. vulgaris leaves proved antioxidant, anticancer, antihypertensive, hepatoprotective, nephroprotective, wound healing, and anti-inflammatory activities. [16-23]

Roots of Beta vulgaris are rich in valuable, active compounds such as carotenoids, glycine betaine, saponins, betacyanines, folates, betanin, polyphenols and flavonoids. [24-28] Consumption of red beet which are rich source of antioxidants can contribute to protection from age-related diseases. According to Vinson, Hao, Su, and Zubik [1998] Žitňanová et al. [2006] red beet is one of the most potent vegetables with respect to antioxidant activity. [29-30] Betacyanins are a group of compounds exhibiting antioxidant and radical-scavenging activities. ${ }^{[31]}$

Several reports are available about the gastroprotective effects are associated with plant extracts that are rich in antioxidants. [32] Although many of the pharmacological and biochemical actions of flavonoids are attributed to their activities as antioxidants [33] Flavonoids were also reported to act in the gastrointestinal tract, having antiulcer potential. [34] Considering the important role of flavonoids in the prevention or reduction of gastric lesions induced by different ulcerogenic agents, the present study was aimed to determine the antiulcer activity of methanol extract of roots of Beta vulgaris using established methods.

\section{MATERIALS AND METHODS}

\section{Drugs and chemicals}

All the drugs, chemicals, and reagents were procured from Qualigens Fine chemicals, Mumbai, India. Omeprazole were obtained from Glaxo Pharmaceuticals, Mumbai. All the chemicals used were of analytical grade.

\section{Preparation of extract}

The roots of Beta vulgaris were collected from local market of Nashik and authenticated at the Agharkar Research Institute, Pune. The roots were cleaned with water. The chopped pieces were subjected to maceration with $1 \%$ methanolic $\mathrm{HCl}$ (methanol $495 \mathrm{ml}$ and $\mathrm{HCl} 5 \mathrm{ml}$ ) for two days with frequent shaking the macerating flask. The macerated product was then air dried for removal of menthol. The extract

\section{Phytochemical investigation}

Phytochemical tests were carried out to find out the presence of phytoconstituents viz flavonoids, saponins, glycosides, alkaloids, carbohydrate, tannins, phenols etc. [35]

\section{Animals}

Adult albino Wistar rats of either sex, weighting 150 $200 \mathrm{~g}$ obtained from Serum Institute Pune, India, were used for the experiment. They were housed in polypropylene cages lined with husk, renewed every 48 hours, under 12:12 hours light dark cycle at around $25 \pm$ $5^{\circ} \mathrm{C}$. They were fed with commercial pellet rat chow and given water ad libitum. The animal care maintained according to the guidelines of the committee for the purpose of control and supervision of experiments on animals (CPCSEA), New Delhi, India, and the protocol of this study was approved by the Animal Ethical Committee of College (Reg. No. MGVIPC/CPCSEA/XXIX/1/2014).

Acute Toxicity study in mice ( $\mathrm{LD}_{50}$ determination) Individual animals were administered dosage at interval of 24 hours. The methanolic extracts of Beta vulgaris roots were given with minimum dose to animals and observed for next 24 hours. If no mortality was seen then the dose was increased. The extracts 
were administered in doses 50, 100, 200, 500, 800, 1000, 1500 , and $2000 \mathrm{mg} / \mathrm{kg}$ p.o. [36]

Experimental Design

Induction of acute ulcer by pyloric-ligation method Adult albino rats of Wistar strain of either sex weighing 150-250 g were used for the study.

All the animals were divided in to the four groups with five animals in each group.

Group I: Control (pyloric ligation)

Group II: Standard receives drug Omeprazole (20 $\mathrm{mg} / \mathrm{kg}$, p.o.)

Group III: Methanolic extract of Beta vulgaris (200 $\mathrm{mg} / \mathrm{kg}$, p.o.)

Group IV: Methanolic extract of Beta vulgaris (400 $\mathrm{mg} / \mathrm{kg}$, p.o.)

They were fasted overnight and placed on wire mesh to avoid coprophagy. Next day they were anaesthetized with anesthetic ketamine. Incision of $1 \mathrm{~cm}$ long was given in the abdomen just below the sternum and stomach was exposed. A thread was passed around the pyloric sphincter and a tight knot was applied. The abdomen wall was closed by putting the sutures. The methanolic extract of Beta vulgaris and standard drug Omeprazole were given orally. After 4 hours of pyloric ligation all the animals were sacrificed by large dose of chloroform. Abdomen was opened and oesophageal end was tied and stomach was removed and the contents were drained in a centrifuge tube. Stomach was cut opened along the greater curvature and pinned on a cork plate and observed under magnification (10X) for morphological evaluation of mucosa. [37]

The number of ulcers was noted and the severity recorded with the following

Scores: 0.5- Red coloration, 1-Spot ulcer, 1.5Hemorrhagic streak, 2-Ulcers, 3-Perforation

Mean ulcer score for each animal was expressed as ulcer index.

The volume of the gastric content was measured. After centrifugation, acidity was determined by titration with $0.1 \mathrm{~N} \mathrm{NaOH}$ (sodium hydroxide)

Acidity $(\mathrm{mEq} / \mathrm{l} / 100 \mathrm{~g})$ can be expressed as:

Acidity $=\quad$ Volume of $\mathrm{NaOH} \times$ Normality

Gastric volume, acidity of the gastric content, $\mathrm{pH}$ and ulcer index of treated animals were compared with controls.

Free Acidity: Pipette $1 \mathrm{ml}$ of filtered gastric content into a small beaker. Add 2-3 $\mathrm{ml}$ of water \& then a drop of Topfers indicator. It will turn pink in presence of free $\mathrm{HCl}$. Titrate it with $\mathrm{N} / 100 \mathrm{NaOH}$ until pink colour disappear and colour becomes yellowish orange $(\mathrm{pH} 4)$. At this $\mathrm{pH}$ all free $\mathrm{HCl}$ is titrated. Take burette reading. The volume of alkali requires titration represent free $\mathrm{HCl}$ present in $1 \mathrm{ml}$ gastric juice. Calculate as N/10 acid present in $100 \mathrm{ml}$ of gastric juice.

Total acidity: Add drop of phenolphthalein to above content \& continue titration with the alkali until a definite red reappear $(\mathrm{pH}$ 8.5). Take the difference between this reading \& the initial reading represent the total acid present in $1 \mathrm{ml}$ of gastric content.

Ethanol induced gastric lesion

Male Wistar rats weighing 250-300 g are deprived of food $24 \mathrm{~h}$ prior to the experiment but are allowed free access to water. During this time they are kept in restraining cages to prevent coprophagy.

All the animals were divided in to the four groups with five animals in each group.

Group I: Control receives distilled water $(50 \mathrm{ml} / \mathrm{kg}$, p.o.)

Group II: Standard receives Omeprazole $(20 \mathrm{mg} / \mathrm{kg}$, p.o.)

Group III: Methanolic extract of Beta vulgaris (200 $\mathrm{mg} / \mathrm{kg}$, p.o.)

Group IV: Methanolic extract of Beta vulgaris (400 $\mathrm{mg} / \mathrm{kg}$, p.o.)

The rats are administered either the vehicle or the standard drug orally $30 \mathrm{~min}$ prior to administration of 1 $\mathrm{ml}$ absolute ethanol. Untreated animals are included as controls. One hour after administration of ethanol, the animals are euthanized with ketamine, the stomachs are excised, cut along the greater curvature, and gently rinsed under tap water. The stomachs are stretched on a piece of foam core mat, mucosal site up. The subjective scores of the treated tissues are recorded. [38] The numbers of ulcers were noted and the severity recorded with the following scores:

0.5-Red coloration, 1-Spot ulcer, 1.5-Hemorrhagic streak, 2-Ulcers, 3-Perforation

Mean ulcer score for each animal was expressed as ulcer index.

The volume of the gastric content was measured. After centrifugation, acidity was determined by titration with $0.1 \mathrm{~N} \mathrm{NaOH}$.

\section{Cold restraint stress induced ulcers}

Male Wistar rats weighing 250-300 g are deprived of food 24 hours prior to the experiment but are allowed free access to water. During this time they are kept in restraining cages to prevent coprophagy.

All the animals were divided in to the four groups with five animals in each group.

Group I: Control receives ethanol $(50 \mathrm{ml} / \mathrm{kg}$, p.o.)

Group II: Standard receives Omeprazole $(20 \mathrm{mg} / \mathrm{kg}$, p.o.)

Group III: Methanolic extract of Beta vulgaris (200 $\mathrm{mg} / \mathrm{kg}$, p.o.)

Group IV: Methanolic extract of Beta vulgaris (400 $\mathrm{mg} / \mathrm{kg}$, p.o.)

The rats after 1 hour of pre-treatment with standard drug and extract were subjected to cold stress in restrain cages that were placed at $2-4^{\circ} \mathrm{C}$ in refrigerator for 2 hours. The animals were sacrificed 2 hours later and the ulcer index was determined. Gastric juice was collected and its volume, $\mathrm{pH}$, free acidity, total acidity and percentage inhibition was determined. [39]

The numbers of ulcers were noted and the severity recorded with the following scores: 
Manoj Jagannath Jagtap et al. / Antiulcer Activity of Methanolic Extract of Roots of Beta vulgaris...........

Table 1: Effect of Beta vulgaris on gastric content, $\mathrm{pH}$, acidity and ulcer index in pylorus-ligated rats

\begin{tabular}{|c|c|c|c|c|c|c|}
\hline $\begin{array}{l}\text { Treatment Groups } \\
\text { (Dose in } \mathrm{mg} / \mathrm{kg} \text { ) }\end{array}$ & $\begin{array}{l}\text { Total gastric } \\
\text { content }(\mathrm{ml})\end{array}$ & $\mathrm{pH}$ & $\begin{array}{l}\text { Free acidity } \\
(\mathrm{mEq} / \mathrm{L})\end{array}$ & $\begin{array}{c}\text { Total acidity } \\
(\mathrm{mEq} / \mathrm{L})\end{array}$ & Ulcer Index & $\%$ Inhibition \\
\hline Control (pyloric-ligation) & $3.20 \pm 0.95$ & $3.15 \pm 0.19$ & $45.0 \pm 5.7$ & $75 \pm 31.00$ & 40.3 & - \\
\hline Omeprazole (20) & $1.80 \pm 0.20^{*}$ & $3.87 \pm 0.28^{*}$ & $27.5 \pm 5.0^{*}$ & $35 \pm 5.70^{*}$ & 1.4 & $96.52 \%$ \\
\hline MEBV (200) & $1.10 \pm 0.77^{*}$ & $3.92 \pm 0.45^{*}$ & $22.5 \pm 5.0^{*}$ & $40 \pm 8.16^{*}$ & 12.5 & $68.98 \%$ \\
\hline MEBV (400) & $1.37 \pm 0.47^{*}$ & $4.42 \pm 0.44$ & $12.5 \pm 5.0^{*}$ & $25 \pm 5.77^{*}$ & 0 & $100 \%$ \\
\hline
\end{tabular}

MEBV: Methanolic extract of Beta vulgaris; Values are expressed as mean \pm S.E.M. One way analysis of variance (ANOVA- Dunnett test); ${ }^{*}$ Statistically significant compared with control group $(p<0.05)$

Table 2: Effect of Beta vulgaris on gastric content, $\mathrm{pH}$, acidity and ulcer index in ethanol induced rats

\begin{tabular}{|c|c|c|c|c|c|c|}
\hline $\begin{array}{l}\text { Treatment Groups } \\
\text { (Dose in } \mathrm{mg} / \mathrm{kg} \text { ) }\end{array}$ & $\begin{array}{l}\text { Total gastric } \\
\text { content }(\mathrm{ml})\end{array}$ & $\mathrm{pH}$ & $\begin{array}{c}\text { Free acidity } \\
(\mathrm{mEq} / \mathrm{L})\end{array}$ & $\begin{array}{l}\text { Total acidity } \\
(\mathrm{mEq} / \mathrm{L})\end{array}$ & $\begin{array}{l}\text { Ulcer } \\
\text { Index }\end{array}$ & $\%$ Inhibition \\
\hline Control (ethanol $5 \mathrm{ml} / \mathrm{kg}$ ) & $3.40 \pm 0.46$ & $2.30 \pm 0.12$ & $110.0 \pm 12.2$ & $185.0 \pm 11.90$ & 68.8 & \\
\hline Omeprazole (20) & $1.90 \pm 0.33^{*}$ & $3.87 \pm 0.02^{*}$ & $47.5 \pm 12.5^{*}$ & $118.8 \pm 9.65^{*}$ & 13.2 & $80.8 \%$ \\
\hline MEBV (200) & $2.10 \pm 0.14^{*}$ & $3.65 \pm 0.08^{*}$ & $35.0 \pm 6.45^{*}$ & $110.0 \pm 21.60^{*}$ & 22.75 & $66.93 \%$ \\
\hline MEBV (400) & $1.65 \pm 0.17^{*}$ & $4.42 \pm 0.14^{*}$ & $22.5 \pm 6.29^{*}$ & $45.0 \pm 5.70^{*}$ & 2.1 & $96.94 \%$ \\
\hline
\end{tabular}

MEBV: Methanolic extract of Beta vulgaris; Values are expressed as mean \pm S.E.M. One way analysis of variance (ANOVA- Dunnett test); ${ }^{*}$

Statistically significant compared with control group $(p<0.05)$

Table 3: Effect of Beta vulgaris on gastric content, $\mathrm{pH}$, acidity and ulcer index in Cold stress induced rats

\begin{tabular}{|c|c|c|c|c|c|c|}
\hline $\begin{array}{l}\text { Treatment Groups } \\
\text { (Dose in } \mathrm{mg} / \mathrm{kg} \text { ) }\end{array}$ & $\begin{array}{l}\text { Total gastric } \\
\text { content }(\mathrm{ml})\end{array}$ & $\mathrm{pH}$ & $\begin{array}{l}\text { Free acidity } \\
(\mathrm{mEq} / \mathrm{L})\end{array}$ & $\begin{array}{l}\text { Total acidity } \\
(\mathrm{mEq} / \mathrm{L})\end{array}$ & Ulcer Index & $\%$ Inhibition \\
\hline Control & $4.23 \pm 0.14$ & $3.033 \pm 0.03$ & $70 \pm 5.00$ & $83.33 \pm 8.81$ & 24.5 & \\
\hline Omeprazole (20) & $3.867 \pm 0.03^{*}$ & $3.633 \pm 0.13^{*}$ & $16.67 \pm 3.33^{*}$ & $43.33 \pm 3.33^{*}$ & 0 & $100 \%$ \\
\hline MEBV (200) & $1.533 \pm 0.31^{*}$ & $3.83 \pm 0.20^{*}$ & $33.33 \pm 3.3^{*}$ & $53.33 \pm 3.33^{*}$ & 0 & $100 \%$ \\
\hline MEBV (400) & $1.33 \pm 0.35^{*}$ & $4.60 \pm 0.1^{*}$ & $26.67 \pm 6.66^{*}$ & $46.67 \pm 3.33$ & 0 & $100 \%$ \\
\hline
\end{tabular}

MEBV: Methanolic extract of Beta vulgaris; Values are expressed as mean \pm S.E.M. One way analysis of variance (ANOVA- Dunnett test); * Statistically significant compared with control group $(p<0.05)$

0.5-Red coloration, 1-Spot ulcer, 1.5-Hemorrhagic streak, 2-Ulcers, 3-Perforation

Mean ulcer score for each animal was expressed as ulcer index.

The volume of the gastric content was measured. After centrifugation, acidity was determined by titration with $0.1 \mathrm{~N} \mathrm{NaOH}$.

\section{Statistical analysis}

The mean \pm SEM values were calculated for each group. One-Way ANOVA followed by Dunnett's multiple comparison tests were used for statistical analysis. The results were statistically analyzed by Graphpad Instat Software. Values $p<0.05$ was considered statistically significant.

\section{RESULTS}

The methanolic extract of roots of Beta vulgaris was subjected for phytochemical investigation and $L_{50}$ studies. It was found that methanolic extract contained flavonoids, saponins, sterols, and alkaloids. The extract was tested for their lethal effect up to the dose level of $2000 \mathrm{mg} / \mathrm{kg}$. None of them have produced abnormal behavior or mortality in rats.

Animals in the control group (pyloric-ligation) showed ulceration of gastric mucosa and more than 5 ulcers were observed. Administration of methanolic extract of roots of Beta vulgaris produced significant $(p<0.01)$ decrease in ulcer index and also significantly reduced the gastric volume, total acidity, and increased the $\mathrm{pH}$ of the gastric fluid, proving its anti-secretary activity when compared with control group. Omeprazole also significantly $(p<0.01)$ reduced ulcer index, gastric volume, total acidity, and increased the $\mathrm{pH}$ of the gastric fluid, of pyloric-ligation induced gastric ulcers.
Pylorus-ligation produced gastric lesions in the gastric mucosa of the control group (Group I). Administration of methanolic extract of Beta vulgaris (Group III, Group IV) reduced these lesions as evidenced by a significant $(p<0.01)$ reduction in the ulcer index when compared with the control group. Omeprazole (Group II) also significantly $(p<0.01)$ reduced ulcer index of pylorus ligated-induced gastric ulcers.

Administration of ethanol produced haemorrhagic gastric lesions in the gastric mucosa of the control group (Group I). Administration of methanolic extract of Beta vulgaris (Group III, Group IV) reduced these lesions as evidenced by a significant $(p<0.01)$ reduction in the ulcer index when compared with the control group. Omeprazole (Group II) also significantly $(p<0.01)$ reduced ulcer index of ethanol-induced gastric ulcers.

Cold stress induced produced gastric lesions in the gastric mucosa of the control group (Group I). Administration of methanolic extract of Beta vulgaris (Group III, Group IV) reduced these lesions as evidenced by a significant $(p<0.01)$ reduction in the ulcer index when compared with the control group. Omeprazole (Group II) also significantly $(p<0.01)$ reduced ulcer index of Cold stress -induced gastric ulcers.

\section{DISCUSSION}

Pyloric ligation induced ulcers caused due to imbalance between offensive and defensive mucosal factors are ideal model to infer the mechanism by which a drug works as an anti ulcerogenic agent. [40] The activation of the vagus-vagal reflux by stimulation of pressure receptors in the antral gastric mucosa in the hyper 
secretion model of pylorus ligature is believed to increase gastric acid secretion. [41] The causes of gastric ulcer in pyloric ligation are believed to be due to stress induced increase in gastric hydrochloric acid secretion and/or stasis of acid and the volume of secretion is also an important factor in the formation of ulcer due to exposure of the unprotected lumen of the stomach to the accumulating acid. [42] Studies have shown alterations in the antioxidant status following ulceration, indicating that free radicals seem to be associated with the pylorus ligation-induced ulceration in rats. The present study demonstrated the potential of MEBV (200) and MEBV (400) to significantly reduced gastric ulceration as indicated by the reduction in ulcer index in pyloric ligation model by $68.98 \%$ and $100 \%$ when compared to control.

Ethanol is responsible for disturbances in gastric secretion, damage to the mucosa, alterations in the permeability, gastric mucus depletion and free radical production. The generation of free radicals was produced by continuous release of superoxide anion and hydroperoxy free radicals during metabolism of ethanol. [43] Ethanol induced gastric ulceration may be occurred due to stasis in gastric blood flow which contributes to the development of the hemorrhage and necrotic tissue injuries. Alcohol has ability to penetrate the gastric mucosa and causing the cellular damage which increases the permeability to sodium and water. In other hand, the accumulation of intracellular calcium causes the pathogenesis of gastric injury that leads to cell death and exfoliation of surface epithelium. ${ }^{[44]}$ The present study observed that the MEBV significantly reduced ethanol induced ulcer by cytoprotective action via antioxidant effect. The methanol extract showed cytoprotection against the ethanol induced ulceration by reducing the gastric acid secretion. [45] The present study demonstrated the potential of MEBV (200) and MEBV (400) to significantly reduced gastric ulceration as indicated by the reduction in ulcer index in ethanol induced ulceration by $66.93 \%$ and $96.94 \%$ when compared to control.

Cold restraint causes both psychological and physical stress to the rats. The induced stress releases histamine in the stomach, which leads to increased acid secretion and decreased mucus production, ultimately leading to ulcers. ${ }^{[46]}$ MEBV caused a dose-dependent significant reduction in the ulcer index in this model.

The significant increase in the antiulcer activity of Beta vulgaris could be attributed to the presence of flavonoids, alkaloids, tannins, saponins glycosides and phenolic compounds. Flavonoids are among the cytoprotective materials for which antiulcerogenic efficacy has been extensively confirmed. It is suggested that, these active compounds would be able to stimulate mucus, bicarbonate and the prostaglandin secretion and counteract with the deteriorating effects of reactive oxidants in gastrointestinal lumen. ${ }^{[47]}$ So the antiulcer activity of Beta vulgaris may be attributed to its flavonoids content. The present findings conclude that Root extract of Beta vulgaris has significant antiulcer activity as it exhibited protective effect on gastric ulcer in rats.

\section{ACKNOWLEDGEMENT}

We are thankful to management of Mahatma Gandhi Vidyamandir's Institute of Pharmacy, Nashik, Maharashtra for the providing the digital library and all facilities for carried out this work.

\section{REFERENCES}

1. Bandyopadhyay D, Biswas K, Bhattacharyya M, Reiter RJ, Banerjee RK. Gastric toxicity and mucosal ulceration induced by oxygen-derived reactive species, protection by melatonin. Current Molecular Medicine. 2001; 1:501-513.

2. Bhattacharjee M, Bhattacharjee S, Gupta A, Banerjee RK. Critical role of an endogenous gastric peroxidase in controlling oxidative damage in $H$. pylori-mediated and nonmediated gastric ulcer. Free Radical Biology \& Medicine. 2002; 32:731-743.

3. Konturek PC, Konturek S. Role of Helicobacter pylori infection in gastro-duodenal secretion and in pathogenesis of peptic ulcer and gastritis. Journal of Physiology and Pharmacology. 1994; 45: 333-350.

4. Wallace JL, Granger DN. The cellular and molecular basis of gastric mucosal defense. Federation of American Societies for Experimental Biology. 1996; 10:731-740.

5. Nash J, Lambert L, Deakin M. Histamine $\mathrm{H}_{2}$-receptor antagonists in peptic ulcer disease. Evidence for a prophylactic use. Drugs. 1994; 47: 862-871.

6. Hoogerwerf WA, Pasricha PJ. Agents used for control of gastric acidity and treatment of peptic ulcers and gastroesophageal reflux disease. In: Hardman JG, Limbird LE, Gilaman AG (Eds.), The Pharmacological Basis of Therapeutics, (10 th edn). Mc Graw-Hill, New York; 2001. pp. 1005-1019.

7. Gisbert JP. Potent gastric acid inhibition in Helicobacter pylori eradication. Drugs. 2005; 65(1): 83-96.

8. Jones J, Raud J. Nonsteroidal anti-inflammatory drugassociated dyspepsia: basic mechanisms and future research. American journal of Medicine. 2001; 110: 14S-18S.

9. Falcão HS, Mariath IR, Diniz MF, Batista LM, Barbosa-Filho JM. Plants of the American continent with antiulcer activity. Phytomedicine 2008; 15:132-46.

10. Jesus NZ, Falcão HS, Lima GR, Caldas Filho MR, Sales IR, Gomes IF, et al. Hyptis suaveolens (L.) Poit (Lamiaceae), a medicinal plant protects the stomach against several gastric ulcer models. Journal of Ethnopharmacology. 2013; 150:9828.

11. Singh B, Hathan BS. Chemical composition, functional properties and processing of Beetroot - a review. International Journal of Scientific \& Engineering Research. 2014; 5(1): 679-684.

12. Jugdutt B. Cyclooxygenase inhibition and adverse remodeling during healing after myocardial infarction. Circulation. 2007; 115: 288-291.

13. Kirtikar KR, Basu BD. Indian Medicinal Plants, Vol. III, Periodical Experts, Delhi, India; 1975. pp. 2310-2311.

14. Bias HP, Madhusudhan R, Bhagyalakshmi N, Rajashekaran $\mathrm{T}$, Ramesh BS, Ravishankar GA. Influence of polyamines on growth and formation of secondary metabolites in hairy root cultures of Beta vulgaris and Tagetes patula. Acta Physiol. Plantarum. 2000; 22:151.

15. Anonymous.The Wealth of India. Dictionary of Indian Raw Materials and Industrial Products. Volume IV, Revised Edition, CSIR, Publication and Information Directorate, New Delhi; 1988. pp. 141-146.

16. Gamal AA, Said MS, Raish M, Sohaibani M, Massarani SM, Ahmad A, et al. Beetroot (Beta vulgaris L.) extract ameliorates 
gentamicin-induced nephrotoxicity associated oxidative stress, inflammation, and apoptosis in rodent model. Mediators Inflamm. 2014; 22: 133-145.

17. Jain S, Garg VK, Sharma PK. Anti-inflammatory activity of aqueous extract of Beta vulgaris L. Journal of Basic and Clinical Pharmacy. 2011; 2: 83-89.

18. Sulakhiya K, Patel VK, Saxena R, Dashore J, Srivastava AK, Rathore M. Effect of Beta vulgaris Linn. leaves extract on anxiety-and depressive-like behavior and oxidative stress in mice after acute restraint stress. Pharmeutical Research. 2016; 8: 11-12.

19. Jain NK, Singhai AK. Protective role of Beta vulgaris L. leaves extract and fractions on ethanol-mediated hepatic toxicity. Acta Poloniae Pharmaceutica. 2012; 69: 945-950.

20. Bolkent Ş, Yanardağ R, Tabakoğlu-Oğuz A, Özsoy-Saçan Ö. Effects of chard (Beta vulgaris L. var. cicla) extract on pancreatic $B$ cells in streptozotocin-diabetic rats: a morphological and biochemical study. Journal of Ethnopharmacology. 2007; 73: 251-259.

21. Mroczek A, Kapusta I, Janda B, Janiszowska W. Triterpene saponin content in the roots of red beet (Beta vulgaris L.) cultivars. Journal of Agricultural and Food Chemistry. 2012; 60: 12397-12402.

22. Babu VA, Gowri R. Evaluation of antioxidant activity of Beta vulgaris root extract in rats. Asian Journal of Chemistry. 2010; 22: $3385-90$

23. Sacan O, Yanardag R. Antioxidant and antiacetylcholinesterase activities of chard (Beta vulgaris L. var. cicla). Food and Chemistry Toxicology. 2010; 48: 12751280.

24. Dias MG, Camoes MFGFC, Oliveira L. Carotenoids in traditional Portuguese fruits and vegetables. Food Chemistry. 2009; 113: 808-815

25. de Zwart FJ, Slow S, Payne RJ, Lever M, George PM, Gerrard JA, Chambers ST. Glycine betaine and glycine betaine analogues in common foods, Food Chemistry 2003; 83:197204 .

26. Atamanova A, Brezhneva TA, Slivkin AI, Nikolaevskii VA, Selemenev VF, Mironenko NV. Isolation of saponins from table beetroot and primary evaluation of their pharmacological activity. Pharmaceutical Chemistry Journal. 2005; 39(12): 650-652,.

27. Jastrebova J, Witthoft C, Grahn A, Svensson U, Jagerstad M. HPLC determination of folates in raw and processed beetroots. Food Chemistry. 2003; 80:579-588.

28. Vali L, Stefanovits-Banyai E, Szentmihalyi K, Febel H, Sardi E, Lugasi A, Kocsis I, Blazovics A. Liver-protecting effects of table beet (Beta vulgaris var. Rubra) during ischemiareperfusion. Nutrition. 2007; 23: 172-178

29. Vinson JA, Hao Y, Su X, Zubik L. Phenol antioxidant quantity and quality in foods: Vegetables. Journal of Agricultural and Food Chemistry. 1998; 46:3630-3634.

30. Žitňanová I, Ranostajová S, Sobotová H, Demelová D, Pecháň I, Ďuračková Z. Antioxidative activity of selected fruits and vegetables. Biologia. 2006; 61:279-284.
31. Escribano J, Pedreño MA, García-Carmona F, Muñoz R. Characterization of the antiradical activity of betalains from Beta vulgaris L. roots. Phytochemical Analysis. 2008; 9:124127.

32. Awaad AS, El-Meligy RM, Soliman GA. Natural Products in Treatment of Ulcerative Colitis and Peptic Ulcer. Journal of Saudi Chemical Society. 2013; 17:101-124.

33. Larson RA. The antioxidants of higher plants Phytochemistry 1998; 27: 969-978.

34. La Casa C, Villegas I, Alarcon De La Lastra C, Motilva V, Martin Calero MJ. Evidence for protective and antioxidant properties of rutin, a natural flavone, against ethanol induced gastric Lesions. Journal of Ethnopharmacology. 2000; 71:4553.

35. Khandelwal KR. Preliminary phytochemical screening. Practical Pharmacognocy: Techniques and Experiments. 19th ed. Pune: Nirali Publisher; 2008.

36. OECD. Guideline 425: Acute Oral Toxicity. Environmental health and safety monograph series on testing and assessment No. 24; 2001.

37. Shay H, Komarov SA, Fels SS, Meranze D, Grunstein M, Siplet H, A Simple method for uniform production of gastric ulcers in rats. Gastroenterology. 1945; 5: 43-61.

38. Moraisa TC, Pintoa NB, Karine Maria MB, Carvalhob JBR, Ricardoc MTS, et al. Protective effect of anacardic acids from cashew (Anacardium occidentale) on ethanol-induced gastric damage in mice. Chemico-Biological Interactions. 2010; 183: 264-269.

39. Koo MWL, Cho $\mathrm{CH}$, Ogle CW. Effects of cold-restraint stress on gastric ulceration and motility in rats. Pharmacology Biochemistry and Behavior. 1986; 25(4):775-779.

40. Jainu M, Chennam SSD. Antiulcerogenic and ulcer healing effects of Solanum nigrum (L.) on experimental ulcer models: Possible mechanism for the inhibition of acid formation. J Ethnopharmacol. 2006; 104:156 63.

41. Bafna PA, Balaraman R. Anti-ulcer and antioxidant activity of DHC-1, a herbal formulation. J Ethnopharmacol. 2004; 90:123-7.

42. Ngouela S, Tsamo E, Sondengam BL. Extractives from Bignoniaceace: constituents of stem bark of Spathodea campanulata. Planta Med, 1998; 54(5):476.

43. Jude EO, Paul A. Antiulcer and Anticonvulsant Activity of Croton Zambesicus. J Pharm Sci. 2009; 22:384-90.

44. Dwivedi V, Chander BS, Yadav NH. Evaluation of anti-ulcer activity of Clitorea ternatea Leaves (Linn) extract in Wistar rats. Indian Journal of Research in Pharmacy and Biotechnology. 2014; 3:1225-29.

45. Deshpande SS, Shah GB, Parmar NS. Antiulcer activity of Tephrosia purpurea in rats. Indian Journal of Pharmacology. 2003; 35:168-72

46. Glavin GB, Paré WP, Sandbak T, Bakke HK, Murison R Restraint stress in biomedical research: an update. Neuroscience Biobehaviar Review. 1994; 18:223-249.

47. Sakat SS, Juvekar RA. Antiulcer Activity of Methanol Extract of Erythrina indica Lam. Leaves in Experimental Animals. Pharmacognosy Research. 2009; 1: 396-401.

HOW TO CITE THIS ARTICLE: Jagtap MJ, Deore AB. Antiulcer Activity of Methanolic Extract of Roots of Beta vulgaris, Chenopodiaceae. Int. J. Pharm. Sci. Drug Res. 2018; 10(6): 454-459. DOI: 10.25004/IJPSDR.2018.100605 